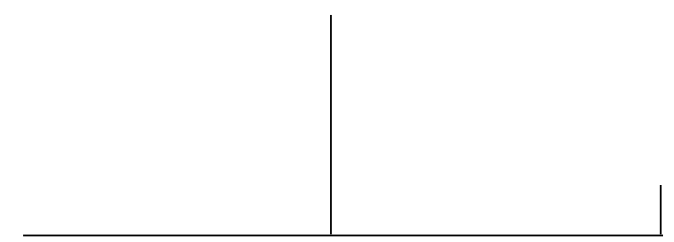

Rev. Latinoam. Psicopat. Fund., São Paulo, v. 15, n. 1, p. 197-202, março 2012

Tornar-se mãe de seu próprio filho

Regina Orth de Aragão

Curitiba: Editora Honoris Causa, 2011, 108 págs.

\title{
Tornar-se mãe de seu próprio filho
}

\author{
Isabel da Silva Kahn Marin
}

Ponto de partida, primórdios. Enigmas do humano, que a clínica psicanalítica não se furta a enfrentar, mesmo que partindo do princípio de que se trata de uma ilusão, "da necessidade de um mítico ponto zero, ponto da origem, que recobre nossa fantasia mais arcaica sobre a origem de nós mesmos, da qual a fantasia da cena primitiva e de nossa concepção seria uma representação possível." O título da obra que Regina Aragão nos sugere é, em si, uma provocação: o nascimento de um bebê por si só não torna uma mulher mãe, nem o bebê um sujeito. $\mathrm{O}$ bebê que vem ao mundo, marca um momento inédito, apesar de toda herança que carrega e é, por assim dizer, um estrangeiro que, como tão sensivelmente Regina irá discutir, pede acolhimento em sua cultura para poder ser civilizado. A mulher que o pariu será assim responsável por esse momento fundante de acolhimento, mas precisará descobrir e interpretar as expressões desse chegante para que ele se civilize de acordo com o esperado por todos os que fazem parte de sua cultura. Nasce um bebê, e uma mulher pode 
ou não se tornar e se reconhecer mãe daquela cria. Questões talvez conhecidas para os psicanalistas, mas que esbarram com mitos sociais absolutamente arraigados em nossa cultura. A angústia da orfandade, o desamparo suscitado quando não se tem certeza das origens, acompanhaM a humanidade e não faltam narrativas que testemunham essa questão. Gostaríamos de pensar que apenas os órfãos "legais" precisassem ser adotados e só nessa condição se encontrariam os desafios para uma mulher tornar-se mãe de um filho, que não foi por ela gerado.

Nesse sentido, o livro de Regina Aragão é fundamental, pois resgata não apenas o movimento dialético constituinte do sujeito humano, mas se constitui na legítima tradição freudiana da pesquisa em psicanálise que é de construir teoria a partir dos sentidos que se constroem no encontro enigmático com cada sujeito, essência do tratamento psicanalítico. A questão que norteou a pesquisa relatada, [...] como se transmitem entre mãe e bebê, os conteúdos inconscientes que farão marca no psiquismo nascente do infans" origina-se na rica experiência da autora em sua clínica com crianças, na escuta de pais, mães, bebês, do trabalho com cuidadores; enfim, de sua prática e reflexões sobre o mundo constituinte do sujeito. Foi movida por essas inquietações, que a autora desenvolveu sua dissertação de mestrado no contexto do Laboratório de Psicopatologia Fundamental do Programa de Estudos Pós-Graduados em Psicologia Clínica da PUC-SP, coordenado pelo prof. dr. Manoel Tosta Berlinck, sendo o texto aqui apresentado fruto desse trabalho. Sua escritura se inscreve na tradição legítima da Psicopatologia Fundamental, ou seja, construir um discurso sobre o Pathos do psiquismo; pathos, entendido como sofrimento, paixão, padecimento, manifestação da subjetividade do humano. Ora, o nascimento marca de forma inexorável essa questão "ser mãe, padecer no paraíso", evoca o senso comum. Regina recupera no seu texto, de forma muito sensível e original, o movimento do constituir-se humano. "Toda criação de um outro humano envolve a violência do encontro com o outro, envolve o risco de jogar-se numa empreitada para a qual não se tem garantia, apesar de todos os progressos da medicina e da ciência atual." Dessa forma, como lembra a autora, pathos como excesso de paixão, se faz presente em todo nascimento, tocando ao mesmo tempo nas dimensões da criação, da morte e do sexo. Regina, nesse texto, testemunha a intensidade dos encontros de uma mulher com sua maternidade, de uma mulher com seu bebê, em vida ou em espera, da analista com uma criança, de uma criança com o seu mundo; enfim, de um campo de experiências, de um lugar de observação e de cuidado da paixão humana e todas as suas desmesuras.

A experiência clínica da autora transpira no texto. O diálogo que faz com os diferentes autores que se dedicaram às questões desenvolvidas, revela todo ri- 
gor necessário para uma pesquisa acadêmica, sem, entretanto, aplicar teoria para explicar seus "achados". Há uma verdadeira "harmonização afetiva" Stern (2000) entre as experiências clínicas da autora e os conceitos que utilizará para compreender e analisar as questões que se apresentam, revelando a essência mesma do método clínico psicanalítico.

Não pude deixar de lembrar Conrad Stein (1988): "Basta que um paciente venha se deitar com hora marcada no divã de um psicanalista para que se esboce uma situação cuja promessa é, no fim das contas, de restaurar a mesma glória primordial que se supõe perdida por causa do nascimento. Glória primordial da qual aparece como substituto o laço inalterável que une, no outro, uma mãe e seu filho" (p. 65). Afinal o percurso da autora nesse trabalho: construção do espaço psíquico materno e de suas transformações durante a gestação, com a interrogação a respeito dos possíveis efeitos dessa construção sobre o psiquismo nascente do bebê retoma, a meu ver, o paradigma da constituição subjetiva, referida a dinâmica da transferência que ocorre entre paciente e analista em uma psicanálise.

Convoco então o leitor a acompanhar a organização do texto para que se deixe afetar pelas ricas e instigantes reflexões às quais a autora nos conduz.

O recorte clínico do tratamento de um menino "tão inteligente que vai muito mal na escola" apresentado no capítulo II - De mãe e de filhos, nos introduz às questões centrais do trabalho: constituição do aparelho psíquico e sua função; a inter-relação entre o psiquismo materno e a constituição do psiquismo do bebê, o lugar do terapeuta e os efeitos possíveis do tratamento. Nas reflexões suscitadas pelo caso, Regina evoca construções teóricas sobre a relação inicial mãe-bebê, percorrendo diversos autores, que vão se encarregar de compreender os determinantes da constituição do psiquismo como, por exemplo, pensar a constituição edípica de partida dos pais como decisiva para a constituição edípica de chegada (Bleichmar, 1983), além da complexa questão da ambivalência fundamental no laço mãe-bebê.

O capítulo III vai tratar do psiquismo materno durante a gestação, a partir de fragmentos de análise de uma paciente grávida, especialmente seus sonhos. $\mathrm{O}$ trabalho de transformar o estrangeiro em familiar, forma interessante que Regina propõe para pensar o complexo processo da gravidez e todas suas ressonâncias narcísicas, seria, a meu ver, o eixo das análises propostas. O diálogo com Monique Bydlowski, Cramer e Piera Aulagnier, entre outros, nesse capítulo, é muito interessante por resgatar as tensões do encontro da mulher com sua intimidade e fantasmas mais arcaicos, assim como a possibilidade de antecipação de um Eu caracterizando a gestação como um tempo intermediário entre os fantasmas e os desejos do passado e as projeções do futuro. Evidencia-se como é es- 
sencial a capacidade de lidar com o ainda por vir, portanto o inédito, o desconhecido, o que leva tempo para se apresentar. Daí a noção de estrangeiridade que retorna à inquietante familiaridade.

No capítulo IV defrontamo-nos com a instigante questão sobre a capacidade dos bebês em suportar e reagir à vulnerabilidade. Os efeitos decisivos do encontro da criança com seu cuidador primordial são discutidos em sua interface com a noção de resiliência, conceito decisivo para se compreender as situações-limite e colocar em questão a posição do bebê em relação à alteridade: passividade, receptividade ou "competência"? Regina, de forma original, dialoga com psicanalistas mais tradicionais como Bion, retomando o conceito de rêverie materna, passando por Cramer e Winnicott, e com teóricos do Apego, como Fonagy para resgatar a interessante ideia de assumir que o bebê deve se encontrar em um ambiente que pensa, apoiado no pensamento de muitos outros que acreditam que ele pensa.

Novamente um caso clínico vai organizar o capítulo $\mathrm{V}$ em torno de importantes reflexões sobre os arranjos psíquicos de uma criança diante de situações de vida de extrema precariedade, aprofundando assim as questões suscitadas anteriormente. O sugestivo título "Dor, pele psíquica e função materna" anuncia o desenvolvimento proposto pela autora, em torno da ideia de que a função materna, que se exerce no estado de desamparo fundamental do Infans, vem introduzir Eros no corpo até então ignorado. Em outras palavras, pensar que o psiquismo se constitui no encontro do corpo com a relação. As mais recentes pesquisas sobre as impressões sensoriais que o feto e o bebê recebem do ambiente são consideradas e se aliam aos diferentes aportes que os psicanalistas trazem em relação à pulsionalidade, para tecer as análises propostas em relação ao despertar da pulsionalidade no corpo do bebê.

O capítulo VI aborda a clínica do autismo, analisando e aprofundando, novamente a partir de um caso clínico, as características da relação mãe-bebê, procurando discutir os riscos para o psiquismo do bebê quando se trata de uma mãe deprimida. A discussão retoma de forma contundente a importância da fantasia do Eu antecipado, para preparar a chegada do bebê. Há falas da mãe da criança analisada, muito significativas, que apontam para sua percepção de que o desenvolvimento de uma criança deveria seguir um ritmo natural. Representa-se como uma mãe da natureza, aquela que empresta seu corpo para as funções naturais. "Deveriam ensinar às mães que o prazer com o filho é muito importante, deveriam ensinar às mães que o relacionamento afetivo também é fundamental para o desenvolvimento das crianças", é uma fala da paciente. Ensinar afeto? Como a falta de algo da ordem da identificação materna, da possibilidade de transmissão da função materna pode ser ensinada? Questões instigantes, desenvolvidas pela autora a partir das ressonâncias transferenciais do tratamento da criança e da es- 
cuta de sua mãe. Retorna-se à questão do narcisismo para ajudar na compreensão das relações entre pais e filhos, entre mãe e sua criança, compondo o campo da intersubjetividade.

O desenvolvimento do pensamento da autora leva-a, no próximo capítulo, a discutir a relação mãe-filha e os percalços da possível transmissão da maternalidade de uma para outra. Propõe que essa transmissão está marcada pela construção de ambas, da própria feminilidade, ou seja, pelas marcas de suas trajetórias psicossexuais. Retoma então as teses freudianas e os diversos e intensos debates que se seguiram entre os psicanalistas sobre a sexualidade feminina, e da ligação entre feminilidade e maternidade. Analisa de forma muito interessante o sentimento de inquietante estranheza (unheimleich) que assola a mulher na gravidez, justamente por retomar sua relação primordial com a mãe da origem; a questão da fusão/diferenciação entre mãe e filha, o luto pelo objeto de amor primeiro, a difícil identificação com a mãe - que traz para a menina o testemunho da renúncia e também da rejeição a esse primeiro objeto de amor - vão marcar eternamente de ambivalência a vivência de maternidade. Nessa perspectiva, as análises desenvolvidas propondo o feto como metáfora do objeto interno em função de sua dupla valência, narcísica e objetal, explicitam claramente como toda angústia relativa ao estranho familiar é suscitada. O bebê apresenta um duplo status: presente no interior do corpo da mãe e em seu fantasma, mas ausente na realidade visível. O bebê como objeto eminentemente narcísico que existe sem existir.

As experiências clínicas da autora no tratamento da criança autista e na escuta de sua paciente grávida, expressam de forma contundente a dinâmica do reencontro com a mãe das origens. A loucura materna normal traz de volta antigos ferimentos narcísicos. Assim, traumatismos, lutos e a herança transgeracional são tornados mais acessíveis em razão do enfraquecimento do recalque. Regina nos apresenta nesse texto justamente as sutilezas do encontro mãe-bebê, analisando o quanto essa loucura é, paradoxalmente, condição para a constituição subjetiva desse chegante. Nessa perspectiva é um convite para que o leitor se deixe tocar pelo enigma que cada nascimento convoca: é a chegada de um novo humano na cultura, por assim dizer um estrangeiro, que pede acolhimento. Acontecimento ao mesmo tempo familiar e misterioso. A dependência radical do bebê pode ser insuportável, ao mesmo tempo que fascinante; pode preencher o vazio, alimentando a onipotência de seu cuidador, o que é um risco para a autonomia do chegante, mas também convoca o rico processo de socialização. Por isso, destaco a importância das reflexões da autora sobre a noção de estrangeiridade que retorna com a inquietante familiaridade. $\mathrm{Na}$ atualidade, onde a temporalidade parece estar marcada pelo instantâneo e as ilusões de controle são quase realizadas 


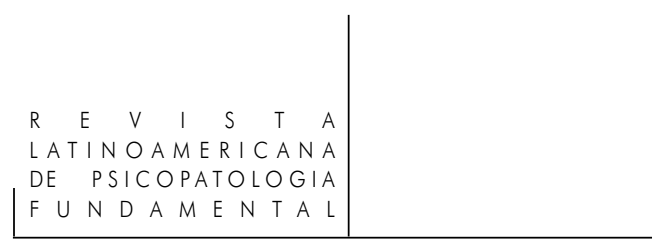

(imagens ultrassonográficas cada vez mais perfeitas, por exemplo), a exposição ao desconhecido gera muita ansiedade. Pode-se pensar que o processo de antecipação imaginária fica comprometido, o que traz questões importantes sobre os efeitos disso no psiquismo nascente do bebê. Por essa razão, o livro de Regina é fundamental. Oferece parâmetros preciosos para orientar a escuta clínica e o acolhimento, nos inícios da vida.

\section{Referências}

Bleichmar, S. Nas origens do sujeito psíquico. Porto Alegre: Artes Médicas, 1983.

Stein, C. As eríneas de uma mãe. Ensaio sobre o ódio. São Paulo: Escuta, 1988.

Stern, D. Verbete harmonização afetiva. In: Houzel, D.; Emmanuelli, M.; Moggio, F. (Orgs.). Dictionnaire de psichopathologie de l'Enfant et de l'Adolescent. Paris: PUF, 2000.

\section{Isabel da Silva Kahn Marin}

Psicóloga; doutora em Psicologia Clínica pela Pontifícia Universidade Católica de São Paulo - PUC-SP (São Paulo, SP, Br.); psicanalista e professora da Faculdade de Psicologia da mesma universidade; pesquisadora do Laboratório de Psicopatologia Fundamental; autora dos livros Febem, família e identidade. O lugar do Outro (São Paulo: Escuta, 1999, 2a ed. revisada) e Violências (São Paulo: Escuta, 2003).

Rua Antonina, 241

01255-010 São Paulo, SP

Fone: (11) 3873-2359

e-mail: bel.kahn@terra.com.br

Rua Capote Valente, 439/113

05409-001 São Paulo, SP

Fone: (11) 3081-1829 - Fax: (11) 3062-5981

Rev. Latinoam. Psicopat. Fund., São Paulo, v. 15, n. 1, p. 197-202, março 2012 